\title{
Author reply to comments
}

Sir,

We appreciate the comments of Animesh Ray. However, majority of the points raised by him have already been alluded to in the review. ${ }^{[1]}$ Following is our reply to their remarks.

1. The conventional classification of chest tuberculosis (CTB) into primary and post-primary forms helps to understand the pathogenesis of the disease and its manifestations. Though there are typical imaging features described for both, nevertheless, there is considerable overlap in the radiological patterns, as already discussed in our article. ${ }^{[1,2]}$ Also, since the article focuses on imaging features, molecular studies are beyond the scope of the article.

2. As author et al. themselves state that chest radiograph (CXR) has high sensitivity, so it makes sense to employ it as an initial imaging modality, keeping in view its wide availability, low cost, and substantially less radiation. In a considerable proportion of patients, CXR along with clinical and laboratory findings would help to diagnose TB accurately and CT would be unnecessary. In the remaining patients where CXR is equivocal and/or the clinical and laboratory findings are non-contributory, CECT is justified and is the investigation of choice. Thus, CT cannot be advocated in all smear-negative patients. We agree that a section of patients (like those infected with retrovirus) usually need a CECT chest and abdomen to rule out TB (both pulmonary and extra-pulmonary) and other opportunistic infections. However, this was beyond the scope of the current article.

3. Sputum culture may be done along with smear microscopy where facilities are available and where smear examination is equivocal. We agree that Gene Xpert MTB/RIF serves as a helpful add-on test, especially in cases of smear-negative TB (because of its increased sensitivity) and to detect rifampicin resistance (in previously treated cases and contacts of drug-resistant TB patients). ${ }^{[3,4]}$ However, high costs and limited availability hamper the routine use. There is no definite data to justify its use in treatment-naïve, non-retroviral infected patients, and this test may have false-positive results due to detection of dead bacilli.

4. In case of radiological worsening of CTB and no definite clinical improvement, we have suggested doing a CT first to assess disease activity. ${ }^{[1]}$ This will also serve to rule out alternative diagnosis. If CT suggests residual disease activity, then intensive phase of ATT may be prolonged. At this point of time, other relevant investigations/therapies may be instituted to detect drug resistance and to treat any secondary infection. The point is well-taken that clinical/radiological worsening despite treatment should lead one to proceed with an exhaustive work-up to find the cause. We wish to highlight here that the suggested protocols may be modified depending on clinical judgment on a case-to-case basis.

5. It goes without saying that imaging findings are always interpreted in conjunction with clinical features. If there is high index of suspicion and in case of immunocompromised patients where there may be atypical radiological findings, other investigations such as bronchoalveolar lavage and tissue/fluid sampling frequently prove beneficial. Also, adequate work-up to rule out alternative diagnoses is essential in case of atypical imaging features.

The purpose of the suggested recommendations is to enable judicious use of imaging in diagnosis and follow-up of CTB patients, with the caveat that they may need to be customized to the given clinical situation.

Financial support and sponsorship

Nil.

\section{Conflicts of interest}

There are no conflicts of interest. Ashu Seith Bhalla, Ankur Goyal, Randeep Guleria',
Arun Kumar Gupta
Departments of Radiodiagnosis, and 'Pulmonary Medicine,
All India Institute of Medical Sciences, New Delhi, India
E-mail: ashubhalla1@yahoo.com 


\section{References}

1. Bhalla AS, Goyal A, Guleria R, Gupta AK. Chest tuberculosis: Radiological review and imaging recommendations. Indian J Radiol Imaging 2015;25:213-25.

2. Van Dyck P, Vanhoenacker FM, Van den Brande P, De Schepper AM. Imaging of pulmonary tuberculosis. Eur Radiol 2003;13:1771-85.

3. Steingart KR, Schiller I, Horne DJ, Pai M, Boehme CC, Dendukuri N. Xpert ${ }^{\circledast}$ MTB/RIF assay for pulmonary tuberculosis and rifampicin resistance in adults. Cochrane Database Syst Rev 2014;1:CD009593.

4. National Guidelines on Diagnosis and Treatment of Pediatric Tuberculosis. Available from: http://www.tbcindia.nic. in/Paediatric\%20guidelines_New.pdf. [Last accessed on 2015 Aug 13].
This is an open access article distributed under the terms of the Creative Commons Attribution-NonCommercial-ShareAlike 3.0 License, which allows others to remix, tweak, and build upon the work non-commercially, as long as the author is credited and the new creations are licensed under the identical terms.

\begin{tabular}{|l|l|}
\hline \multicolumn{2}{|c|}{ Access this article online } \\
\hline Quick Response Code: & \\
\hline & Website: \\
\hline
\end{tabular}

Cite this article as: Bhalla AS, Goyal A, Guleria R, Gupta AK. Author reply to comments. Indian J Radiol Imaging 2015;25:475-6. 